\title{
A Literature Survey of the Chemistry of Flame Inhibition
}

\author{
E. C. Creitz \\ Institute for Applied Technology, National Bureau of Standards, \\ Washington, D.C. 20234
}

(April 6, 1970)

\begin{abstract}
Evidence is beginning to accumulate indicating that catalytic recombination of oxygen atoms may be the mechanism of extinction of flames by halogenated extinguishing agents. The literature of flame inhibition and of oxygen atom chemistry has been examined to ascertain whether the available data would support such a mechanism. Considerable sustentative evidence was found.

Kinetic rate-constant data are not available covering all reactions of interest, but those that are reported indicate that catalytic recombination of oxygen atoms can probably compete successfully with normal flame processes which require them.
\end{abstract}

Key words: Flame chemistry; flame extinction; flame inhibition.

\section{Introduction}

The study of the chemistry of fires is usually viewed as an exercise in fuel chemistry. This viewpoint is somewhat surprising since the oxidant, rather than the fuel, is the feature common to nearly all such fires. Likewise, in the study of the extinction of unwanted fires, the fuel appears to have received nearly all the attention. An examination of literature on the chemistry of atomic oxygen revealed a single reference [1], ${ }^{1}$ in which it was suggested that the effects of halogen atoms in recombining oxygen atoms "might have applicability in flame inhibition." The statement was made specifically with respect to I-atoms at $1000 \mathrm{~K}$, which were reported [2] to remove $\mathrm{O}$-atoms from a system some 200 times faster than could NO molecules; and NO had been used in the same system to titrate $\mathrm{O}$-atoms.

A simultaneous study of the literature on $\mathrm{O}$-atom chemistry and the literature on the chemical inhibition of flames gives considerable support to Kaufman's [1] suggestion. The results of such a study are reported herein.

\section{The Point of Attack by the Inhibitor}

The first question to be asked has to do with the way an inhibitor modifies flame characteristics. Kydd and Foss [3] found that, with hydrogen, the rate of heat released in normal flames was independent of the oxygen concentration, $\left[\mathrm{O}_{2}\right]$, if the oxygen was present in excess of stoichiometric proportions. Phillips and

' Figures in brackets indicate the references at the end of the paper.
Sugden [4] reported that 2 percent $\mathrm{Cl}_{2}$ raised the flame temperature 20 to $30^{\circ}$ in premixed $\mathrm{H}_{2}-\mathrm{O}_{2}$ flames, while bromine and iodine had much smaller effects. Bulewicz, Phillips and Sugden [5] and Rosser, Inami and Wise $[6,7]$ report that the addition of inhibitors to flames produced no significant change in flame temperatures. The latter authors observed quite significant changes in quenching distance, however. Lask and Wagner [8], Halpern [9] and Miller, Evers and Skinner [10] related changes in flame speed to the amount of inhibitor and its efficiency. It appears, then that the inhibitor operates primarily by altering reaction rates, rather than the overall flame thermodynamics, i.e., it appears to alter the reaction path without much alteration in the total heat release. However, the rate of fuel consumption in diffusion flames is controlled by rates of diffusion, rather than by reaction rates. The same inhibitors that extinguish premixed flames are effective against diffusion flames and at about the same concentrations, if applied to the air side of diffusion flames [11]. If the same inhibition mechanism is to be proposed for both premixed and diffusion flames, one is forced to consider the near-equilibirum conditions obtaining in diffusion flames.

Diffusion flames may be considered to consist of a series of shells of constant composition, each shell differing in composition from that on each side of it. Reactions in each such shell are thought to be close to equilibrium because of the speed of chemical reactions compared to the rates at which reactants can be supplied to the shell. Within the shell, it appears that the logical point of attack is the equilibrium itself. Most such equilibria in flames are attained as the 
result of chain reactions. A reduction of the concentration of a single species, if it is involved in a chain reaction, is a necessary and sufficient condition for the upsetting of any of the equilibria so attained. Diversion of a reactant species to form a product not useful in chain propagation would produce such a disturbance. For example, robbing a hydrogen-oxygen chain of $\mathrm{H}$-atoms by $\mathrm{CF}_{3}$ to form $\mathrm{CF}_{3} \mathrm{H}$, or of $\mathrm{O}$-atoms to form $\mathrm{COF}_{2}$ [12] would effectively break the chain.

The same result could be accomplished by the introduction of additional steps in the chain. For example in the hydrogen-oxygen chain, if the recombination of $\mathrm{O}$-atoms could be speeded up so that it was competitive with other reactions removing $\mathrm{O}$-atoms, the equilibrium would be shifted. The recombination and splitting of oxygen effectively only adds additional steps to the normal chain reaction. Since the reaction would eventually go to completion, as species migrate from shell to shell, one would not expect any great change in the overall flame thermodynamics.

Species derived by pyrolysis of the fuel must migrate outward to reach the reaction zone. Thus, reduction of their concentrations or interference with their diffusion would result in a smaller diameter, longer diffusion flame. This effect is usually observed when the inhibitor is added to the fuel. Species migrating inward toward the reaction zone include $\mathrm{O}_{2}$, and $\mathrm{O}$, as well as some $\mathrm{OH}$ and $\mathrm{HO}_{2}$. Reduction of their concentrations should produce an increase in the diameter of a diffusion flame. This effect is usually observed when the inhibitor is added to the oxygen side of a diffusion flame. Thus, an increase in diameter tends to implicate oxygenated species while a decrease points toward involvement of fuel fragments in the inhibition mechanism.

Experimental results obtained by Rosser, Inami, and Wise [6, 7] indicate that inhibition, in their system, is associated with the use of oxygen as an oxidizer. Some observations by the author indicate that there may be an additional limitation in that the oxygen must be gas phase oxygen. Solid compounds, like perchlorates, appear not to be subject to inhibition by halogen compounds. It appears, also, that inhibition by halogenated compounds may affect only the branching steps of the hydrogen-oxygen chain reactions

$$
\begin{aligned}
& \mathrm{H}_{2}+\mathrm{O} \rightarrow \mathrm{OH}+\mathrm{H}, \\
& \mathrm{O}_{2}+\mathrm{H} \rightarrow \mathrm{OH}+\mathrm{O} .
\end{aligned}
$$

The oxidation of $\mathrm{CO}$ to $\mathrm{CO}_{2}$ is strongly inhibited [13], while the oxidation of $\mathrm{C}$ to $\mathrm{CO}$ appears to be unaffected $[14,15]$ by halogens or their compounds. The oxidation of $\mathrm{CO}$ to $\mathrm{CO}_{2}$ depends in a secondary way on the hydrogen-oxygen chain reaction, since it requires $\mathrm{OH}$ and/or $\mathrm{HO}_{2}$, according to the reactions

$$
\begin{gathered}
\mathrm{CO}+\mathrm{OH} \rightarrow \mathrm{CO}_{2}+\mathrm{H} \quad[16,17] \\
\mathrm{CO}+\mathrm{HO}_{2} \rightarrow \mathrm{CO}_{2}+\mathrm{OH} \quad[18,19] .
\end{gathered}
$$

Evidence for the involvement of the hydrogen-oxygen chain reaction in the mechanism of inhibition is relatively plentiful. The negative evidence, lack of inhibition when the chain reaction is not present, is harder to document, probably because of the paucity of oxidizing gases which will support flames. Available data appear to be limited to the nitrogen oxides.

The involvement of $\mathrm{O}$-atoms in the inhibition mechanism is supported by the observation [20] that the flame speed, in several fuel-oxygen systems, was linearly related to the $[\mathrm{O}]$ : However, the involvement of $\mathrm{O}$-atoms exclusively cannot be supported on this evidence alone, since $\mathrm{O}, \mathrm{H}$, and $\mathrm{OH}$ are expected to be present in near equilibrium concentrations because of the rapid rates, both forward and backward, of reactions 1 and 2 relative to rates of diffusion. The linear relationships between [O] and flame speed provides rather strong support for the involvement of the hydrogen-oxygen chain reaction in the inhibition mechanism, however.

\section{The Nature of the Inhibiting Species}

Skinner and Ringrose [12] came to the conclusion that the intact inhibitor molecule is involved in extinguishment. It is generally believed, however, that the actual inhibition is accomplished by one or more fragments of the inhibitor molecule or their recombination products. In the case of halogenated organic inhibitors the most active fragment is believed to be the halogen $(\mathrm{Cl}, \mathrm{Br}$, or I) atom. Some support for this belief is given by the observation [11] of emission bands associated with the recombination of bromine atoms on the air side of diffusion flames inhibited by $\mathrm{CH}_{3} \mathrm{Br}$. When $\mathrm{Br}_{2}$ was substituted for the $\mathrm{CH}_{3} \mathrm{Br}$, no $\mathrm{Br}_{2}$ emission was seen, but inhibition was still evident. The same system of emission bands was reported [21] in oxygen-rich premixed flames. Fuel rich flames produced emission associated with the excited halogen acid. Much stronger support for the importance of atomic halogen comes from the composition profiles of premixed flames which show [22] that $\mathrm{CH}_{3} \mathrm{Br}$ decomposes at an earlier point in the reaction zone than does the fuel $\left(\mathrm{CH}_{4}\right)$. Preliminary observations of the author indicate that decomposition of $\mathrm{CF}_{3} \mathrm{Br}$ is complete well outside of the reaction zone of a diffusion flame when it is added to the air side. The $\mathrm{CF}_{3}$ radical produced by removal of the bromine atom from $\mathrm{CF}_{3} \mathrm{Br}$ may play a part in inhibition since $\mathrm{COF}_{2}$ and $\mathrm{CF}_{3} \mathrm{H}$ were found [12] in shocked mixtures of $\mathrm{H}_{2}, \mathrm{O}_{2}$, and $\mathrm{CF}_{3} \mathrm{Br}$.

There are several reasons why the halogen acids are not serious contenders for the position of the primary inhibiting species. In diffusion flames, the region outside the reaction zone, where inhibition appears to take place, is an oxygen-rich, recombination region. If the inhibitor molecule contains no hydrogen (such as $\mathrm{CF}_{3} \mathrm{Br}$ ) the only source of hydrogen would be the $\mathrm{H}$-atom, the $\mathrm{OH}$ radical and $\mathrm{HO}_{2}$ radical produced by the flame. The most likely reaction for formation of the halogen acid would be

$$
\mathrm{H}+\mathrm{X}+\mathrm{M} \rightarrow \mathrm{HX}+\mathrm{M} .
$$


This reaction is third order and would be slow compared to the second order flame reactions. It would introduce an extra step in the generation of the inhibiting species so that $\mathrm{CF}_{3} \mathrm{Br}$ would be expected to be less efficient than $\mathrm{HBr}$ itself. The reverse is observed, although part of the effect may be due to the $\mathrm{CF}_{3}$ radical. When the inhibitor is added to the fuel, one would expect that HX would be a common reaction product which would be formed from the inhibitor molecule whether or not it originally contained hydrogen. Emission spectra [21] indicate that this product is actually formed. But the inhibitor (HX), when added to the fuel, is little more effective than the equivalent amount of nitrogen [13]. It would appear that the halogen acids cannot survive the oxidizing conditions in the reaction zone and the region immediately outside it. This would be particularly the case for $\mathrm{HI}$ and $\mathrm{HBr}$, while $\mathrm{HCl}$ would undoubtedly be somewhat more stable under these conditions. In the oxygen-rich recombination region, recombination of $\mathrm{H}$, $\mathrm{OH}$ and $\mathrm{HO}_{2}$ are to be expected as a normal part of the flame processes. Recombination of oxygen atoms in this region would rob the reaction zone of one of its primary reactants. Reactions such as

$$
\mathrm{HX}+\mathrm{OH} \rightarrow \mathrm{X}+\mathrm{H}_{2} \mathrm{O}
$$

are second order recombination reactions for $\mathrm{H}$ and $\mathrm{OH}$, replacing the slower, third order recombination of $\mathrm{H}$ and $\mathrm{OH}$ to form water, and could be important only in that atomic halogen is formed.

It is of interest to speculate on the mechanism of decomposition of inhibitors. Some of them are thermally quite stable. For example, $\mathrm{CF}_{3} \mathrm{Br}$ is prepared commercially by bromination of fluoroform at temperatures of 673 to $873 \mathrm{~K}$, and by brominolysis of perfluoropropane at temperatures of 973 to $1273 \mathrm{~K}$ [23]. Thermal stability, with retention of chemical activity may even be an advantage in an inhibitor. It would permit the inhibitor to approach the reaction zone closely enough to be decomposed by active species in the flame front. Both the decomposition reaction and the decomposition products would, thus, be effective at the most appropriate region of the flame. The most probable species present in this region of a diffusion flame would include such stable compounds as $\mathrm{O}_{2}, \mathrm{CO}_{2}, \mathrm{H}_{2} \mathrm{O}$, and $\mathrm{CO}$, as well as such active species as $\mathrm{O}, \mathrm{H}, \mathrm{OH}$, and $\mathrm{HO}_{2}$. Reactions of inhibitor molecules with the active species appear not to have been extensively studied. The reaction between $\mathrm{O}$-atoms and $\mathrm{CCl}_{4}$ appears to be too slow to compete successfully with flame reactions. The overall reaction rate constant ${ }^{2}$ was found to be $\log k=-13.48-\frac{983}{T}$ by Ung and Schiff [24] over a temperature range of 273 to $373 \mathrm{~K}$.

\footnotetext{
${ }^{2}$ Reaction rates in this paper are quoted in the form $\log _{10} k=A-C / T$ or $\log _{10} k=A+B$ $\log T-C / T$ and are for concentrations in particles $\mathrm{cm}^{-3}$, seconds and degrees Kelvin. The activation energy $E^{*}=2.303 R C$, where $R$ is the gas constant. $R=8.314 \mathrm{~J} \mathrm{~mol}^{-1} \mathrm{~K}^{-1}$; $=1.987 \mathrm{cal} \mathrm{mol}^{-1} \mathrm{~K}^{-1}$. Many of these rate constants are of lower reliability than indicated by the number of significant figures shown for $k, A, B$, and $C$. Assume $\log _{10} k \pm 0.5$ unless by the number of
otherwise stated.

Enthalpies of reaction were calculated from $\Delta H f^{\circ}(298.15 \mathrm{~K})$ data in NBS Technical Note 270-3 (1968). No temperature correction was made. Values are given in $\mathrm{kJ} \mathrm{mol}^{-1}$ and $\mathrm{kcal} \mathrm{mol}^{-1}(\mathrm{l} \mathrm{cal}=4.184 \mathrm{~J})$. An "exothermic reaction" has $\Delta H<0$, and an "endothermic reaction" has $\Delta H>0$.
}

\section{Halogen Atom Reactions With Flame Species}

Reduction of chain branching would have a powerful effect on flame speed. The intermediates $\mathrm{H}, \mathrm{O}, \mathrm{OH}$, and $\mathrm{HO}_{2}$ in the branching hydrogen-oxygen chain reaction are of most interest in the inhibition process. Of these, $\mathrm{OH}$ is probably the most reactive. The emission of the $(\mathrm{O}, \mathrm{O})$ band of $\mathrm{OH}$ has been variously reported to decrease $[6,11,25]$ with addition of inhibitor or to show no effect up to 2 percent $\mathrm{Cl}_{2}$ addition [24]. For fuel side injection of methyl bromide and $\mathrm{POCl}_{3}$, the decrease in $\mathrm{OH}$ emission was more marked than for air side injection [25]. However, air side injection is expected to produce greater amounts of inhibition [11, 13]. Unexpectedly, $\mathrm{CCl}_{4}$ enhanced, rather than reduced the $\mathrm{OH}$ emission with air side injection [25]. Emission studies are not considered to be definitive, however, since the reduced emission can be attributed equally well to a decreased total $[\mathrm{OH}]$ or to simply deactivation of excited $\mathrm{OH}$ without change in the $[\mathrm{OH}]$ concentration. Wilson [22] has shown, on the basis of calculations from thermodynamics and reaction rates, that the $[\mathrm{OH}]$ would be expected to increase with the addition of inhibitor. Direct reaction of halogen atoms with $\mathrm{OH}$ via reactions 7,8 , and 9 can be eliminated on several counts.

$$
\begin{gathered}
\mathrm{Cl}+\mathrm{OH} \rightarrow \mathrm{HCl}+\mathrm{O} \\
\mathrm{Br}+\mathrm{OH} \rightarrow \mathrm{HBr}+\mathrm{O} \\
\mathrm{I}+\mathrm{OH} \rightarrow \mathrm{HI}+\mathrm{O} .
\end{gathered}
$$

The production of $\mathrm{OH}$ is limited by reaction 2, above, [26] which has a rate constant given by $\log k=-9.3$ $-\frac{3665}{T}$ over the temperature range 300 to $2500 \mathrm{~K}$. $\left(k=9.1 \times 10^{-14} \mathrm{~cm}^{3}\right.$ particle ${ }^{-1} \mathrm{~s}^{-1}$ at $\left.1000 \mathrm{~K}\right)$ [27].

The rate of reaction 7 is given by $\log k=-12.48$ $+0.67 \log T-\frac{22}{T}\left(k=3.2 \times 10^{-11} \mathrm{~cm}^{3}\right.$ particle $^{-1} \mathrm{~s}^{-1}$ at $1000 \mathrm{~K}),[28]$ that for reaction 8 by $\log k=-12.02+0.5$ $\log T-\frac{3250}{T}\left(k=1.6 \times 10^{-14} \mathrm{~cm}^{3}\right.$ particle $\mathrm{s}^{-1}$, at $1000 \mathrm{~K}),[28]$ and for reaction 9 by $\log k=-11.96+0.5$ $\log T-\frac{6775}{T}\left(k=5.8 \times 10^{-18} \mathrm{~cm}^{3} \quad\right.$ particle $^{-1} \mathrm{~s}^{-1}$ at $1000 \mathrm{~K})[28]$. The rate of reaction 7 is faster than reaction 2 , reaction 8 about equally fast and reaction 9 is much slower. This order, $\mathrm{Cl}>\mathrm{Br}>\mathrm{I}$, is the reverse of the observed order of efficiencies as inhibitors for the three halogens. Similarly, the enthalpies of the reactions are $-0.90,+14.80$, and $+31.03 \mathrm{kcal} \mathrm{mol}^{-1}$ $\left(-3.8,+61.9\right.$, and $\left.+129.8 \mathrm{~kJ} \mathrm{~mol}^{-1}\right) ;$ also in the opposite order to that found for the efficiencies. Additionally, reactions 7,8 , and 9 would produce $\mathrm{O}$-atoms which should lead to increased flame speed, according to the data of Fenimore and Jones [20]. Direct reaction between halogen atoms and hydroxyl, therefore, appears to be an improbable mechanism of inhibition. 
Inhibition of the $\mathrm{H}_{2}-\mathrm{O}_{2}$ chain by ethylene [29, 30], apparently does not involve $\mathrm{OH}$ radicals or $\left[\mathrm{H}_{2}\right]$, but is linearly dependent on the $\left[\mathrm{O}_{2}\right]$. This view is reasonable, since $\mathrm{OH}$ is a product, not a reactant, in the $\mathrm{H}_{2}-\mathrm{O}_{2}$ chain reaction. At least part of the oxidation of $\mathrm{CO}$ depends on the presence of $\mathrm{OH}$ (reaction 3 ). The inhibition of the $\mathrm{CO}$ oxidation would appear to depend, at least partially, on the reduction of the $[\mathrm{OH}]$ by some means other than by reactions 7,8 , and 9 , since these reactions do not appear to be involved in inhibition.

Abstraction of hydrogen atoms from the fuel, to form the halogen acid, was proposed by Rosser, Wise, and Miller [31] as the first stage in an inhibition mechanism. The second stage suggested was the removal of $\mathrm{O}, \mathrm{H}, \mathrm{OH}, \mathrm{CH}_{3}$, etc., by the halogen acid with regeneration of the halogen atom. Thus, in terms of the hydrogen-oxygen chain reaction, the actual inhibitor would be the halogen acid. Some objections to the halogen acid as the primary inhibitor have been listed above. This mechanism, in effect, substituted a halogen atom for an atom of one of the active flame species. It also required a molecule of fuel for the production of the halogen acid. No such fuel species would be expected in the region where inhibition appears to occur. Fish [32] studied the proposal and concluded that it could be successful only if the active flame species removed was "identically equal to $\mathrm{OH}$." Removal of hydroxyl by the halogen acid has also been suggested by Ibiricu and Gaydon [25]. Their work was based on measurements of the intensity of emission of both excited $\mathrm{OH}$ and excited $\mathrm{CuOH}$. Only one reaction rate has been found for reaction 6 , an order-ofmagnitude estimate, $\log k=-12.8+0.5 \log T-\frac{1303}{T}$ [33], for $\mathrm{X}=\mathrm{Cl}\left(k=2.5 \times 10^{-13} \mathrm{~cm}^{3}\right.$ particle $^{-1} \mathrm{~s}^{-1}$ at $1000 \mathrm{~K})$. Fish [32] states that $k(\mathrm{OH}+\mathrm{HBr}) / k\left(\mathrm{OH}+\mathrm{CH}_{4}\right)$ $=160$ at $785 \mathrm{~K}$ and that $E^{*}(\mathrm{OH}+\mathrm{HBr})=0$. By using the value $k=4.4 \times 10^{-11} \exp (-5000 / R T)$ for $\mathrm{OH}+\mathrm{CH}_{4}$, i.e., $k=3.6 \times 10^{-12}$ at $1000 \mathrm{~K}$, one obtains $k(\mathrm{OH}+\mathrm{HBr})$ $=5.8 \times 10^{-10} \mathrm{~cm}^{3}$ particle ${ }^{-1} \mathrm{~s}^{-1}$ at $1000 \mathrm{~K}$. This makes Tunders estimate [33] doubtful. That work assumed $E^{*}(\mathrm{OH}+\mathrm{HCl})=6 \mathrm{kcal} / \mathrm{mol}$. The enthalpies of reaction, however, are in the correct order, and the reactions are exothermic. $\Delta H_{298}=-11.96,-31.66$, and -47.90 $\mathrm{kcal} \mathrm{mol}^{-1}\left(-50.03,-132.5\right.$, and $\left.-200.4 \mathrm{~kJ} \mathrm{~mol}^{-1}\right)$ for $\mathrm{X}=\mathrm{Cl}, \mathrm{Br}$, and I respectively. The principal objection to the abstraction of $\mathrm{OH}$ as a mechanism of inhibition is that it would shift the equilibria of both reactions 1 and 2 to the right, tending to favor their going to completion.

Removal of H-atoms by the third order reaction with halogen atoms, reaction 5 , is slow as discussed above. Removal of $\mathrm{H}$-atoms by

$$
\mathrm{HX}+\mathrm{H} \rightarrow \mathrm{H}_{2}+\mathrm{X}
$$

implies that the halogen acids should be more efficient inhibitors than compounds which liberate only halogen atoms. In the latter case an additional step would be needed to convert the halogen atom to the corresponding acid. Additionally, the equilibrium for reaction 10 lies far to the left, at least for $\mathrm{X}=\mathrm{Cl}[34]$.
With the hydroperoxyl radical two types of reaction may be postulated.

$$
\mathrm{X}+\mathrm{HO}_{2} \rightarrow \mathrm{XO}+\mathrm{OH}
$$

and

$$
\mathrm{X}+\mathrm{HO}_{2} \rightarrow \mathrm{HX}+\mathrm{O}_{2}
$$

For reaction 11 , the enthalpy of reaction, when $\mathrm{X}=\mathrm{Cl}$, is $-1 \mathrm{kcal}(-4 \mathrm{~kJ}) \mathrm{mol}^{-1}$. For $\mathrm{X}=\mathrm{Br}$ and $\mathrm{I}$, the reaction becomes more endothermic, $\Delta H=+7$ and $+20 \mathrm{kcal}$ $\mathrm{mol}^{-1}\left(+29\right.$ and $\left.+84 \mathrm{~kJ} \mathrm{~mol}^{-1}\right)$ respectively so that this reaction may be discounted as important in inhibition. Reaction 12 is exothermic in all three cases; however. Values calculated for $\mathrm{X}=\mathrm{Cl}, \mathrm{Br}$, I are $\Delta H=-56,-40,-24 \mathrm{kcal} \mathrm{mol}^{-1}(-234,-167$, and $-100 \mathrm{~kJ} \mathrm{~mol}^{-1}$ ), respectively. Little information could be found on the rate constants for either reaction. Jensen [35] gives an estimated rate constant for reaction 12 of $k=2 \times 10^{-11} \mathrm{~cm}^{3}$ particle ${ }^{-1} \mathrm{~s}^{-1}$ over the range 1000 to $3500 \mathrm{~K}$, which indicates a relatively fast reaction. The enthalpies of reaction for both reactions 11 and 12 go in the order $\mathrm{Cl}>\mathrm{Br}>\mathrm{I}$.

In spite of this order, Blackmore, O'Donnell, and Simmons [36] found that $\mathrm{HBr}$ was some 400 times more effective than $\mathrm{HCl}$ as an inhibitor for the second limit of the $\mathrm{H}_{2}-\mathrm{O}_{2}$ reaction. They suggested that the quadratic process, reaction 12 , is a chain terminating reaction for a chain involving recombination of $\mathrm{H}$-atoms by reaction 10, along with some other reaction converting $\mathrm{X}$-atoms into $\mathrm{HX}$. If reaction 12 is chain terminating for a chain that is essentially inhibiting in nature, it cannot itself be an inhibiting reaction.

The hydroperoxyl radical is credited with being the species chiefly responsible for recombination of $\mathrm{O}, \mathrm{H}$, and $\mathrm{OH}$ in the recombination region outside the reaction zone [37]. As such, it is difficult to see how its destruction could result in inhibition. A reduction of its concentration in this region should have the effect of extending the recombination region leaving the reaction zone relatively unaffected. Recombination reactions in the $\mathrm{H}_{2}-\mathrm{O}_{2}$ reaction which do not involve $\mathrm{HO}_{2}$ are third order [38] and slow.

A mechanism of flame inhibition based on $\mathrm{O}$-atom abstraction seems to offer some advantage over abstraction of $\mathrm{H}, \mathrm{OH}$ or $\mathrm{HO}_{2}$. It can explain the lack of inhibition of $\mathrm{CH}_{4}-\mathrm{NO}$ flames by $\mathrm{CF}_{3} \mathrm{Br}$ and $\mathrm{CH}_{3} \mathrm{Br}$, where hydrogen is present but the hydrogen-oxygen chain reaction is not required for the oxidation.

Inhibition of diffusion flames appears to occur in a location where $\mathrm{O}$-atoms would be expected to be abundant. Such a mechanism would offer an explanation for the apparent lack of inhibition observed when the inhibitor is added to the fuel. This mechanism is bolstered somewhat by the reported emission spectra of the halogen monoxides in inhibited flames. The emission occurs at locations in diffusion flames where $\mathrm{O}$-atomis would be expected to be plentiful, and links the probable inhibiting species to a species important in the hydrogen-oxygen chain reaction. The dependence of inhibitor concentration on $\left[\mathrm{O}_{2}\right]$ agrees with such a mechanism, as does the relationship of flame 
speed and [O] [20]. The IO emission intensity has been found to vary smoothly with $[\mathrm{O}]$ and $[\mathrm{OH}]$ in $\mathrm{O}$-atom titration experiments in flames [39].

When halogen compounds are added to the air supplied to diffusion flames, the presence of halogen oxides seems to be indisputible. The first emission spectrum of such compounds was reported in 1929 [40], and a tentative identification of the emitter was made. The identification was confirmed in a series of papers [41-46], but the in-depth study of their kinetics occurred only after the advent of the flash photolysis technique [47]. An excellent review was presented by Porter [48].

Considering the very short lifetimes of the halogen monoxides, a surprising amount of information on them is available. A very thorough study of their absorption spectra was made by Durie and Ramsey [49]. Absorption bands associated with FO were not observed, although a search was made for them by these authors. Electron resonance spectra of $\mathrm{ClO}$ and $\mathrm{BrO}$ have been measured [50]. The first matrix isolation technique applied to $\mathrm{ClO}$ was reported by Norman and Porter $[51,52,48]$. Recently, microwave spectra have been obtained for $\mathrm{ClO}$ [53] and $\mathrm{BrO}$ [54].

Oxygen atoms may take part in both the formation of halogen monoxides and in their subsequent reactions. Reactions of the type

$$
\mathrm{O}+\mathrm{X}+\mathrm{M} \rightarrow \mathrm{OX}+\mathrm{M}
$$

are thermodynamically probable, since the enthalpies of reaction are exothermic, $\Delta H=-64.29,-56.23$ and $-43.25 \mathrm{kcal} \mathrm{mol}^{-1}(-268.9,-235.3$ and $-181.0 \mathrm{~kJ}$ $\mathrm{mol}^{-1}$ ) for $\mathrm{X}=\mathrm{Cl}, \mathrm{Br}$, and $\mathrm{I}$, respectively. The reactions are third order, and could be fast, depending on the number of collisions required for deactivation of the newly formed XO. No information on the rates of these reactions has been found. Reactions of the type

$$
\mathrm{O}+\mathrm{X}_{2} \rightarrow \mathrm{XO}+\mathrm{X}
$$

are more nearly thermoneutral. The enthalpies of reaction are $\Delta H=-6.13,-10.14$ and $-7.09 \mathrm{kcal}$ $\mathrm{mol}^{-1}\left(-25.6,-42.4\right.$ and $\left.-29.7 \mathrm{~kJ} \mathrm{~mol}^{-1}\right)$ for $\mathrm{X}=\mathrm{Cl}$, $\mathrm{Br}$ and I, respectively. Clyne and Coxon [55] determined a rate constant, $\log k=-11.02-\frac{677}{T} \mathrm{~cm}^{3}$ particle $^{-1} \mathrm{~s}^{-1}$ over a temperature range of 174 to $396 \mathrm{~K}$, for $\mathrm{X}_{2}=\mathrm{Cl}_{2}$. This value appears to have been obtained in the absence of molecular oxygen by measurement of the rate of variation of the $[\mathrm{O}]$ in a flow system. No measurements were made of the rate of variation of the [ClO], however. Niki and Weinstock [56] remedied these deficiencies. With the $\left[\mathrm{Cl}_{2}\right]$ larger than the $[\mathrm{O}]$, and in the presence of $\mathrm{O}_{2}$, the latter authors found a rate constant of $\log k=-12.85$ ( $k$ in $\mathrm{cm}^{3}$ particle $^{-1}$ $\mathrm{s}^{-1}$ ) for reaction 14 with $\mathrm{X}_{2}=\mathrm{Cl}_{2}$, at $300 \mathrm{~K}$. Reaction 14 , along with reaction 15 ,

$$
\mathrm{O}+\mathrm{OX} \rightarrow \mathrm{X}+\mathrm{O}_{2}
$$

was considered sufficient to explain the homogeneous reaction between atomic oxygen and molecular chlorine, provided reaction 15 was considerably faster than reaction 14 . The same conclusion was also reached by Clyne and Coxon [57]. The mixing of $\mathrm{O}$ atoms and $\mathrm{Cl}_{2}$ in a microwave spectrometer failed to produce measurable quantities of $\mathrm{ClO}$ [58], indicating that reaction 15 probably is much faster than reaction 14, while a similar experiment with $\mathrm{Br}_{2}$ produced quantities of $\mathrm{BrO}$ ample for measurement. These observations appear to indicate that, when $\mathrm{X}=\mathrm{Br}$, the rate of reaction 14 is comparable to that of reaction 15 . The proposal of Porter and Wright [59] that a peroxy radical, $\mathrm{XOO}$, is part of the reaction chain, thus appears unnecessary to explain reaction 14 .

The existence of $\mathrm{BrOO}$ is doubtful, in any event, because of the weakness of the bromine-oxygen bond in such a compound [60]. The mechanism of formation of $\mathrm{XO}$ by way of $\mathrm{XOO}$ is, additionally, unlikely because the overall reaction is endothermic for $\mathrm{X}=\mathrm{Br}$ and $\mathrm{I}$. It has been found possible [58] to excite oxygen by collision with electrically excited argon. This excited oxygen has been found to react with $\mathrm{Br}_{2}$ to produce $\mathrm{BrO}$. It is not known with certainty what the state of excited oxygen is, but it is believed to be a low level state of molecular oxygen, possibly singlet sigma. It appears to be quite long lived, and very reactive. Such a mechanism for the formation of $\mathrm{BrO}$ in flames needs further investigation. Kaufman's [1] "catalytic" recombination of $\mathrm{O}$-atoms by $\mathrm{Cl}$-atoms has been interpreted by Niki and Weinstock [56] as a wall recombination of Cl-atoms followed by reaction 14 . In the case of iodine at $1000^{\circ}[2]$, there can be no doubt that I-atoms were present, since the equilibrium constant for the dissociation

$$
\mathrm{l} / 2 \mathrm{I}_{2}(\mathrm{~g})=\mathrm{I}(\mathrm{g})
$$

has a value of 0.56 [61]. Molecular iodine was also present, however. Norrish and Thrush [62] found that $\mathrm{ClO}$ was formed 46 times faster than Cl-atoms disappeared by recombination (with $\mathrm{N}_{2}$ as the third body). While there is general agreement that reaction 15 is very fast, the source of the $\mathrm{XO}$ has not been clearly explained.

The possibility of the formation of $\mathrm{XO}$ by the reaction

$$
\mathrm{X}+\mathrm{OH} \rightarrow \mathrm{XO}+\mathrm{H}
$$

was considered and rejected by Phillips and Sugden [21]. The reactions are extremely endothermic, $\Delta H=+38.05,+46.11$ and $+59.09 \mathrm{kcal} \mathrm{mol}^{-1}(+159.2$, +192.9 and $+247.2 \mathrm{~kJ} \mathrm{~mol}^{-1}$ ) for $\mathrm{X}=\mathrm{Cl}, \mathrm{Br}$, and I.

The arguments presented earlier, implicating atomic, rather than molecular halogen as the active inhibiting species, indicate that reaction 13 may actually be faster than reaction 14 as a producer of $\mathrm{XO}$ radicals. The reverse of reaction 15 as a source of XO radicals is improbable for two reasons; the reactions are highly endothermic, $\Delta H=+54.81,+62.87$ and $+75.85 \mathrm{kcal}$ $\mathrm{mol}^{-1}\left(+229.3,+263.0\right.$ and $\left.+317.3 \mathrm{~kJ} \mathrm{~mol}^{-1}\right)$ for $\mathrm{X}=\mathrm{Cl}, \mathrm{Br}$, and I. Secondly, reaction 15 would produce 
O-atoms, which would be expected to increase, rather than decrease, the flame speed.

The proposal that reaction 15 may play a major role in inhibition implies that it is fast compared to other reactions by which $\mathrm{XO}$ might be consumed. The equilibrium should lie far to the right. Broida, Schiff and Sugden [63] suggested that ClO might be a useful titrant for O-atoms. IO and $\mathrm{BrO}$ have been used for this purpose [39]. Accurate reaction rate constants are apparently not available in the open literature. However, a value of $\log k=-10.10\left(k\right.$ in $\mathrm{cm}^{3}$ particle $\left.{ }^{-1} \mathrm{~s}^{-1}\right)$ at $298 \mathrm{~K}$, was given by Clyne and Coxon [55] for X=Cl. Their results also confirm that reaction 15 is fast and stoichiometric, and show that concentrations of $\mathrm{ClO}$ radicals may be measured by a titration with atomic oxygen.

In order that the halogen oxides be effective in removing oxygen atoms, their reactions with other species must be slower than the reactions with $\mathrm{O}$-atoms.

The reaction

$$
\mathrm{ClO}+\mathrm{ClO} \rightarrow \text { Products, }
$$

where the products are eventually $\mathrm{Cl}_{2}$ and $\mathrm{O}_{2}$, is bimolecular in $[\mathrm{ClO}]$ and has a reported rate constant [64] of $\log k=-11.96-\frac{546}{T}$ ( $k$ in $\mathrm{cm}^{3}$ particle ${ }^{-1} \mathrm{~s}^{-1}$ ) over the temperature range 294 to $495 \mathrm{~K}$. This reaction is at least one order of magnitude slower than reaction 15 , for which $k=3.9 \times 10^{-12} \mathrm{~cm}^{3}$ particle $\mathrm{s}^{-1}$ at $1000 \mathrm{~K}$ [35].

The bimolecular reaction between $\mathrm{ClO}$ and $\mathrm{H}_{2}$ to form $\mathrm{OH}+\mathrm{HCl}$ is slow, $\log k=-15.3\left(k\right.$ in $\mathrm{cm}^{3}$ particle ${ }^{-1} \mathrm{~s}^{-1}$ ) at $298 \mathrm{~K}$, [64] and is exothermic to the extent of $\Delta H=-37.09 \mathrm{kcal} \mathrm{mol}^{-1}\left(-155.2 \mathrm{~kJ} \mathrm{~mol}^{-1}\right)$. If $\mathrm{H}_{2} \mathrm{O}+\mathrm{Cl}$ are the products, $\Delta H=-52 \mathrm{kcal}(-218$ $\mathrm{kJ}) \mathrm{mol}^{-1}$. The decay rate of $\mathrm{ClO}$ appeared to be independent of the presence of $\mathrm{H}_{2}$ [64].

Reactions of XO with atomic hydrogen could yield either $\mathrm{O}$ or $\mathrm{OH}$ by reactions

$$
\begin{aligned}
& \mathrm{XO}+\mathrm{H} \rightarrow \mathrm{HX}+\mathrm{O} \\
& \mathrm{XO}+\mathrm{H} \rightarrow \mathrm{X}+\mathrm{OH},
\end{aligned}
$$

and could produce inhibition effects by the interpolation of an additional step in the reaction chain. Both reactions are exothermic. For reaction 18 , with $\mathrm{X}=\mathrm{Cl}$, $\mathrm{Br}$, or I, the enthalpies are $\Delta H=-38.95,-31.31$ and $-28.06 \mathrm{kcal} \mathrm{mol}{ }^{-1}(-163.0,-131.0$ and $-117.4 \mathrm{~kJ}$ $\mathrm{mol}^{-1}$ ). No information on their rates have been found. However, the presence of $\mathrm{IO}^{*}$ in fuel rich flames [21] indicates that its rate of formation must be as fast or faster than its rate of removal in an $\mathrm{H}$-atom-rich environment.

Abstraction of $\mathrm{OH}$, as a mechanism of inhibition, appears to be somewhat questionable, as discussed earlier. The hydroxyl radical is a product, rather than a reactant, in both reactions 1 and 2 . Its removal should increase the yield of both reactions at near-equilibrium conditions. If reactions 1 and 2 lost no $\mathrm{H}$ - or $\mathrm{O}$ - atoms to diffusion, recombination, etc., they could continue to the depletion of $\mathrm{H}_{2}$ and $\mathrm{O}_{2}$. However, $\mathrm{H}$ and $\mathrm{O}$-atoms will be lost in a nonideal system and the chief function of the hydroxyl radical is to replace them by reactions such as

and

$$
\mathrm{OH}+\mathrm{OH} \rightarrow \mathrm{H}_{2} \mathrm{O}+\mathrm{O}
$$

$$
\mathrm{OH}+\mathrm{H}_{2} \rightarrow \mathrm{H}_{2} \mathrm{O}+\mathrm{H} \text {. }
$$

Thus, the hydroxyl radical has a role as a reactant, and its removal could deplete the $[\mathrm{H}]$ and $[\mathrm{O}]$ to the point where reactions 1 and 2 would succumb to such losses. The importance of the $\mathrm{OH}$ radical, therefore, hinges on the factors governing the losses of $\mathrm{H}$ - and $\mathrm{O}$-atoms from reactions 1 and 2. Additionally, the hydroxyl radical, rather than the $\mathrm{O}$-atom, is thought $[65,66]$ to be the species responsible for the primary attack on the fuel molecule. Removal, of the $\mathrm{OH}$ radical could, thus, cause a depletion of the $\mathrm{H}_{2}$ required in reaction 1 .

Bimolecular reactions between the halogen monoxides with $\mathrm{OH}$ may be postulated to yield two different sets of products.

$$
\begin{aligned}
& \mathrm{XO}+\mathrm{OH} \rightarrow \mathrm{HX}+\mathrm{O}_{2} \\
& \mathrm{XO}+\mathrm{OH} \rightarrow \mathrm{X}+\mathrm{HO}_{2} .
\end{aligned}
$$

For reaction 22, the enthalpies are exothermic, $\Delta H=-55.71,-48.07$ and $-44.82 \mathrm{kcal} \mathrm{mol}^{-1}(-233.0$, -201.1 and $-187.5 \mathrm{~kJ} \mathrm{~mol}^{-1}$ ), while for reaction 23 they are $\Delta H=+1,-7$ and $-20 \mathrm{kcal} \mathrm{mol}^{-1}(+4.2$, -29 and $-84 \mathrm{~kJ} \mathrm{~mol}^{-1}$ ) for $\mathrm{X}=\mathrm{Cl}, \mathrm{Br}$ and $\mathrm{I}$, respectively. All are thermodynamically probably except for $\mathrm{X}=\mathrm{Cl}$ in reaction 23 . No rate constant data have been found for any of these reactions.

The poor inhibitor sensitivity observed when the inhibitor is added to the fuel of a diffusion flame seems to be evidence that there is little competition between the inhibitor and the fuel for $\mathrm{OH}$ radicals. However, under these conditions the inhibitor is probably HX rather than $\mathrm{XO}$, because the $[\mathrm{O}] \ll[\mathrm{H}]$ in this part of the flame. IO emission has been observed in fuel rich premixed flames [21]. It is not clear whether the IO observed under these conditions is attributable to an increased population of excited IO over unexcited IO caused by the particular conditions of the experiment. The absence of $\mathrm{ClO}$ and $\mathrm{BrO}$ emission does not preclude the presence of the unexcited radicals. The hydroperoxyl radical probably has no very active role in the inhibition process, except as a possible reactant liberating halogen from the inhibitor molecule. Its reactions with XO are not thermodynamically probable.

$$
\begin{aligned}
& \mathrm{XO}+\mathrm{HO}_{2} \rightarrow \mathrm{HX}+\mathrm{O}+\mathrm{O}_{2} \\
& \mathrm{XO}+\mathrm{HO}_{2} \rightarrow \mathrm{X}+\mathrm{OH}+\mathrm{O}_{2} .
\end{aligned}
$$

Reaction 24 is endothermic by $\Delta H=+9,+16$ and $+19 \mathrm{kcal} \mathrm{mol}^{-1}\left(+38,+67\right.$ and $\left.+79 \mathrm{~kJ} \mathrm{~mol}^{-1}\right)$ for $\mathrm{X}=\mathrm{Cl}, \mathrm{Br}$, and $\mathrm{I}$, respectively. In reaction 25 , only $\mathrm{X}=\mathrm{I}$ is exothermic. The enthalpies are $\Delta H=+9,+3$ 
and $-9 \mathrm{kcal} \mathrm{mol}^{-1}\left(+38,+13\right.$ and $\left.-38 \mathrm{~kJ} \mathrm{~mol}^{-1}\right)$ for $\mathrm{X}=\mathrm{Cl}, \mathrm{Br}$, and $\mathrm{I}$. No reaction rate constants appear to have been determined for these reactions.

\section{Competition for Oxygen Atoms}

Any inhibition mechanism taking place at nearequilibrium conditions by abstraction of an active species is in direct competition with flame reactions which depend on the same species. Therefore, it is necessary to compare the rates of the supposed abstraction reactions in normal flames. O-atom consumption by reaction 1 is relatively fast. Its rate constant is given [27] by $\log k=-10.68-\frac{2054}{T}$, for $k$ in $\mathrm{cm}^{3}$ particle $\mathrm{e}^{-1} \mathrm{~s}^{-1}$. The reaction is endothermic by $\Delta H=+1.86 \mathrm{kcal} \mathrm{mol}^{-1}\left(7.78 \mathrm{~kJ} \mathrm{~mol}^{-1}\right)$. The rate limiting reaction is reaction 2 , which produces the $\mathrm{O}$-atoms required in reaction 1 . Its rate constant is given [27] by $\log k=-9.378-\frac{3665}{T}$ for $k$ in the same units, for a temperature range of 300 to $2500 \mathrm{~K}$. The reaction is slow $\left(9.1 \times 10^{-14} \mathrm{~cm}^{3}\right.$ particle $\mathrm{s}^{-1}$ at $1000 \mathrm{~K})$ and endothermic by $\Delta H=+16.76 \mathrm{kcal} \mathrm{mol}^{-1}$ $\left(+70.1 \mathrm{~kJ} \mathrm{~mol}^{-1}\right)$. The backward reaction

$$
\mathrm{O}+\mathrm{OH} \rightarrow \mathrm{H}+\mathrm{O}_{2}
$$

is the fastest reaction in the hydrogen-oxygen chain. Its rate constant is given [6] by $\log k=-10.57-\frac{43.43}{T}$ in $\mathrm{cm}^{3}$ particle $\mathrm{e}^{-1} \mathrm{~s}^{-1}$ for the temperature range 300 to $3000 \mathrm{~K}$. The reaction occurs at $1 / 10$ to $1 / 20$ the gas kinetic collision frequency. The removal of $\mathrm{O}$-atoms by water molecules is slow relative to reaction 26 .

$$
\mathrm{O}+\mathrm{H}_{2} \mathrm{O} \rightarrow \mathrm{OH}+\mathrm{OH} .
$$

The rate is not known with certainty. Bascomb [67] gives $\log k=-10.15-\frac{3952}{T} \quad\left(k=7.9 \times 10^{-15} \quad\right.$ at $1000 \mathrm{~K}$ ). The reaction is endothermic, $\Delta H=+16.87$ $\mathrm{kcal} \mathrm{mol}^{-1}\left(70.6 \mathrm{~kJ} \mathrm{~mol}^{-1}\right)$. The reaction of an $\mathrm{O}$-atom and water to produce an $\mathrm{H}$-atom and a hydroperoxyl radical is very slow and very endothermic, and need not be considered further $(\log k=-12.8-0.5 \log$ $T-\frac{12,440}{T}[68], \Delta H_{298}=+55 \mathrm{kcal} \mathrm{mol}^{-1},+230 \mathrm{~kJ}$ $\mathrm{mol}^{-1}$ ).

The reaction

$$
\mathrm{O}+\mathrm{CO}_{2} \rightarrow \mathrm{CO}+\mathrm{O}_{2}
$$

is slow except at high temperatures, with log $k=-10.50-\frac{11,800}{T} \quad[69], \quad \Delta H_{298}=+8.082 \quad \mathrm{kcal}$ $\mathrm{mol}^{-1}\left(33.814 \mathrm{~kJ} \mathrm{~mol}^{-1}\right)$. At $1000 \mathrm{~K}$ it is twelve orders of magnitude slower than reaction 26 .

A very fast reaction, consuming $\mathrm{O}$-atoms in the region of a diffusion flame where inhibition takes place, is the reaction

$$
\mathrm{O}+\mathrm{HO}_{2} \rightarrow \mathrm{HO}+\mathrm{O}_{2} \text {. }
$$

The rate constant has been estimated to be greater than $10^{-11} \mathrm{~cm}^{3}$ particle ${ }^{-1} \mathrm{~s}^{-1}[70]$, presumably at room temperature. The reaction is exothermic by $\Delta H=-56$ $\mathrm{kcal} \mathrm{mol}^{-1}\left(-234 \mathrm{~kJ} \mathrm{~mol}^{-1}\right)$.

Other bimolecular reactions consuming $\mathrm{O}$-atoms in normal flames appear either to be too slow or the reactants (such as $\mathrm{H}_{2} \mathrm{O}_{2}$ ) not too probable in the region of concern in diffusion flames.

Third order reactions consuming oxygen atoms appear to be generally too slow to compete successfully with second order reactions.

$$
\mathrm{O}+\mathrm{O}+\mathrm{M} \rightarrow \mathrm{O}_{2}+\mathrm{M}
$$

is extremely exothermic $\left(\Delta H_{298}=-119.106 \mathrm{kcal} \mathrm{mol}^{-1}\right.$, $\left.\left(-498.34 \mathrm{~kJ} \mathrm{~mol}^{-1}\right)\right)$ but slow, log $k=-29.42-\log$ $T-\frac{75}{T}$ for $\mathrm{M}=\mathrm{O}_{2}$ [71]. With regard to reaction 30,

Kaufman [72] remarked that "Ternary gas phase recombination of $\mathrm{O}$-atoms with $\mathrm{Cl}_{2}$ as the third body can be ruled out. They would have to be efficient beyond all reasonable magnitudes and their rate law is in disagreement with the observed bimolecular reaction." The reaction

$$
\mathrm{O}+\mathrm{OH}+\mathrm{M} \rightarrow \mathrm{HO}_{2}+\mathrm{M}
$$

probably has a rate comparable to that of reaction 30 . The rate given by Bahn [68], $\log k=-30.57$ at $300 \mathrm{~K}$, is probably high by a factor of 10 , based on an alternate path from reaction 26 . This reaction is also probably in the region just outside the reaction zone.

Removal of $\mathrm{O}$-atoms by an inhibitor should produce an increase of $[\mathrm{OH}]$ by shifting the equilibrium to the left. However, such an increase has not been conclusively demonstrated. The third order reaction of $\mathrm{O}$ - and $\mathrm{H}$-atoms is slow even though it is exothermic.

$$
\mathrm{O}+\mathrm{H}+\mathrm{M} \rightarrow \mathrm{OH}+\mathrm{M},
$$

$\log k=-29.3-\log \mathrm{T}$ [73], $H_{298}=-102.34 \mathrm{kcal} \mathrm{mol}^{-1}$ $\left(-428.19 \mathrm{~kJ} \mathrm{~mol}^{-1}\right)$. The direct reaction of $\mathrm{O}$-atoms and $\mathrm{CO}$ is not spin conserved [16, discussion].

$$
\mathrm{O}+\mathrm{CO}+\mathrm{M} \rightarrow \mathrm{CO}_{2}+\mathrm{M}
$$

$\log k=-31.6-\frac{764}{T}$ [73], $H_{298}=-128.192 \mathrm{kcal} \mathrm{mol}^{-1}$, $\left(-536.35 \mathrm{~kJ} \mathrm{~mol}^{-1}\right)$. The reaction is too slow appreciably to affect the consumption of $\mathrm{O}$-atoms.

\section{Recombination of Halogen Atoms}

Halogen atoms, if they are to be effective inhibitors, must not disappear by ineffective reactions at rates comparable to the rates of effective inhibition reactions. The third order recombination of halogen atoms is, therefore, of interest. Bromine and iodine atom recombination is about as fast as $\mathrm{O}$-atom recombination at $1000 \mathrm{~K}$. Kaufman [1] reports that "direct recombination (of $\mathrm{O}$-atoms) is so slow that $\mathrm{O}$-atoms react faster with other species in flames." 
On the basis of this estimate it appears that $\mathrm{Br}$ - and I-atoms also have ample opportunity to react with other flame species. For the reaction

$$
\mathrm{X}+\mathrm{X}+\mathrm{M} \rightarrow \mathrm{X}_{2}+\mathrm{M}
$$

the rate constants may be calculated from log $k=-31.26-2.7 \log (T / 300)[74]$ for $\mathrm{X}=\mathrm{Cl}, \quad \mathrm{M}$ $=\mathrm{Cl}_{2} ; \log k=-30.67-3.01 \log (T / 300) \quad$ [75] for $\mathrm{X}=\mathrm{Br}, \quad M=\mathrm{Br}_{2} ; \quad \log \quad k=-35.54+\log T+1150 / T$ [76] for $\mathrm{X}=\mathrm{I}, \mathrm{M}=\mathrm{I}_{2}$. All three reactions are exothermic. For $\mathrm{X}=\mathrm{Cl}, \mathrm{Br}$ and $\mathrm{I}$, respectively $\Delta H_{298}$ $=-58.164, \quad-46.095$ and -36.147 kcal mol-1 $\left(-243.36,-192.86\right.$ and $\left.-151.24 \mathrm{~kJ} \mathrm{~mol}^{-1}\right)$.

The structure of inhibited diffusion flames gives clues to the chemical processes going on in them. The "auxiliary reaction zone," which forms outside the main reaction zone of some inhibited flames when the inhibitor is added to the air side, has been identified as due to the recombination of halogen atoms [11]. It is not present when molecular halogen is used as the inhibiting agent. Presumably, there is a paucity of halogen atoms inside the extra reaction zone compared to the region outside it. Thus, there is an implication that, if inhibition takes place inside the extra reaction zone, reactions of molecular halogen must be responsible for most of the action, especially with $\mathrm{X}=\mathrm{Cl}$.

If atomic halogen is responsible for inhibition, the action must take place at about the position of the extra reaction zone.

Since the extra reaction zone occurs some little distance outside the main reaction zone, inhibiting reactions of atomic halogen must occur at somewhat larger distances from the main reaction zone. However, the addition of small quantities of NO to the air supplied to a diffusion flame in this laboratory provided evidence, through the yellow-green emission of excited $\mathrm{NO}_{2}$, that $\mathrm{O}$-atoms also exist at large distances from the main reaction zone. The extra reaction zone may be taken as evidence that halogen atoms are present in this region in amounts larger than equilibrium concentrations. It is further evidence of the decomposition of the inhibitor, since the extra reaction zone is absent when the inhibitor is molecular halogen. In the latter case, the equilibrium is approached from the opposite direction. It may be argued that the increased effectiveness of $\mathrm{CF}_{3} \mathrm{Br}$ over $\mathrm{Br}_{2}$ (on the basis of equivalent amounts of $\mathrm{Br}$ ) is attributable to the $\mathrm{CF}_{3}$ radical. It may be argued equally well that the effect is caused by the above-equilibrium $\mathrm{Br}$-atom concentrations occurring when $\mathrm{CF}_{3} \mathrm{Br}$ is used. In practice, it may even be both.

It may be noted in passing, that, at a given temperature, equilibrium concentrations of I-atoms would be greater than $\mathrm{Cl}$-atoms, with $\mathrm{Br}$-atom concentrations between the two [61]. Neglecting any chemical differences, this characteristic of the halogens is sufficient to establish the observed order of efficiencies, $\mathrm{I}>\mathrm{Br}>\mathrm{Cl}$.

Only at high temperatures, where all three halogens are very nearly completely dissociated, and the differences in degree of dissociation become negligible, would chemical differences outweigh the differences in equilibrium atom concentration.

\section{Nonhalogenated Inhibitors}

The suggested attack on oxygen atoms may possibly explain the inhibiting effect of such compounds as $\mathrm{Fe}(\mathrm{CO})_{5}, \mathrm{~Pb}\left(\mathrm{C}_{2} \mathrm{H}_{5}\right)_{4}$ and the alkali metal carbonates. In the case of iron pentacarbonyl, the evidence for recombination of $\mathrm{O}$-atoms is fairly direct. Kaufman [72] reported that, in the presence of O-atoms, $\mathrm{Fe}(\mathrm{CO})_{5}$ produced finely divided oxide which deposited on the walls of the reaction tube causing it to be heated to incandescence by the vigorous recombination reaction. The deposited iron oxide caused recombination of $\mathrm{O}$-atoms in the absence of further addition of $\mathrm{Fe}(\mathrm{CO})_{5}$. One would expect the suspended oxide to perform similarly. The addition of $\mathrm{Fe}(\mathrm{CO})_{5}$ to the fuel and oxygen sides of diffusion flames appears not to have been tried, but its effect on flame speed in premixed flames is well documented $[7,8]$. The addition of the alkali carbonates to the fuel and oxygen sides of diffusion flames also appears not to have been tried. In either case, the positive nature of the metal would prevent the formation of stable compounds with fuel fragments, (with the possible exception of $\mathrm{OH}$ ), so that such experiments would tend to be less definitive than when halogenated compounds are used.

It may be noted that the ease of formation and the stabilities of peroxides of the alkali metals increases with molecular weight, as does the extinguishing efficiency of the carbonates. McEwan and Phillips [77] have observed the superoxides of $\mathrm{Na}, \mathrm{K}$, and $\mathrm{Cs}$ but not of $\mathrm{Li}$ in oxygen-rich premixed flames. They interpreted their results in terms of the reaction

$$
\begin{aligned}
(\mathrm{Na}, \mathrm{K}, \mathrm{Cs})+ & \mathrm{O}_{2} \\
& +\mathrm{M} \rightarrow\left(\mathrm{NaO}_{2}, \mathrm{KO}_{2}, \mathrm{CsO}_{2}\right)+\mathrm{M} .
\end{aligned}
$$

In the sense that it contains no chlorine, bromine or iodine, hexafluoroacetone will be considered with the nonhalogen containing inhibitors. This compound is known to produce large quantities of thermal $\mathrm{CF}_{3}$ free radicals. While no analyses of combustion products were made (see however [12]), it was found [78] that hexafluoroacetone was a quite acceptable inhibitor. Its efficiency was found to be a function of the $\left[\mathrm{O}_{2}\right]$ when added to the oxidant and it was ineffective when added to the fuel $\left(\mathrm{H}_{2}\right)$. It is probable that it operates by abstraction of both $\mathrm{H}$ - and $\mathrm{O}$-atoms, by a nonchain process, to form $\mathrm{CF}_{3} \mathrm{H}$ and $\mathrm{COF}_{2}$. Thus, the efficiency of $\mathrm{CF}_{3} \mathrm{Br}$ must be divided between the $\mathrm{CF}_{3}$ and the $\mathrm{Br}$ fragments of the molecule.

\section{Some Other Implications of Diffusion Flame Structure}

The concentration of $\mathrm{H}_{2}$ would be expected to increase toward the fuel side of the reaction zone, while the $[\mathrm{O}]$ would be expected to decrease. Thus, reaction 1

$$
\mathrm{H}_{2}+\mathrm{O} \rightarrow \mathrm{OH}+\mathrm{H}
$$


would be expected to go through a maximum somewhere fairly close to the fuel. This maximum defines a "reaction zone" for reaction 1. Because H-atoms can diffuse considerably faster than $\mathrm{O}$-atoms, one would expect that the "reaction zone" for reaction 2

$$
\mathrm{O}_{2}+\mathrm{H} \rightarrow \mathrm{OH}+\mathrm{O}
$$

would be somewhat outside that for reaction 1. A chain composed of reactions 2 and 21 has been suggested [79]. Reaction 21,

$$
\mathrm{OH}+\mathrm{H}_{2} \rightarrow \mathrm{H}_{2} \mathrm{O}+\mathrm{H}
$$

is fast, its rate being given [80] by $\log k=-11.17-\frac{878}{T}$. At $1000 \mathrm{~K}$

$$
\begin{aligned}
k_{1} & =1.9 \times 10^{-13} \\
k_{2} & =9.1 \times 10^{-14} \\
k_{21} & =8.9 \times 10^{-13} .
\end{aligned}
$$

At $2000 \mathrm{~K}$ the rates are nearly equal,

$$
\begin{aligned}
k_{1} & =2 \times 10^{-12} \\
k_{2} & =6 \times 10^{-12} \\
k_{21} & =2.5 \times 10^{-12} .
\end{aligned}
$$

In the chain involving reactions 2 and 21, O-atoms are an unused product species. Any theory of inhibition based on oxygen atoms could not apply to this chain. However, reaction 21 , like reaction 1 , must occur toward the fuel side of the overall reaction zone. Its position, with respect to reaction 1 , will be determined by the availability of reactants and the relative rates of the two reactions (i.e., the local temperature). In any event the reaction zone applicable to reaction 21 will be well inside that for reaction 2 , and the arguments for the effectiveness of the inhibitor when applied to the two sides of the overall reaction zone still apply. In fact, the presence of two reactions, each requiring $\mathrm{H}_{2}$ as a reactant might even increase the separation between the zones for reaction 2 and reactions $1+21$, because both 1 and 21 produce hydrogen atoms which would increase the concentration gradient responsible for diffusion of $\mathrm{H}$-atoms.

It is obvious that a great deal remains to be learned about the structure of diffusion flames. It has been calculated [81] that the rate of propagation of the flame front in diffusion flames is directly related to the rate of diffusion of $\mathrm{H}$-atoms. Since the transport of $\mathrm{H}$-atoms is affected by many parameters, it would seem probable that there should be available many direct approaches to flame extinguishment. Recombination of oxygen atoms appears to be a somewhat roundabout way of accomplishing the desired result.

\section{References}

[1] Kaufman, F., Progress in reaction kinetics 1, 3-39 (1961).
[2] Kaufman, F., Gerri, N. J., and Bowman, R. E., J. Chem. Phys. 25, 106-15 (1956).

[3] Kydd, H. P., and Foss, W. I., Tenth Symposium (International) on Combustion pp. 101-110 (1965). The Combustion Institute, Pittsburgh.

[4] Phillips, L. F., and Sugden, T. M., Canadian J. Chem. 38, 1804-8 (1960).

[5] Bulewicz, E. M., Phillips, L. F., and Sugden, T. M., Trans. Faraday Soc. 57, 921-31 (1961).

[6] Rosser, W. F., Jr., Inami, S. H., and Wise, H., Wright Air Development Center Tech Report 59-206 (April 1965).

[7] Rosser, W. A. Jr., Inami, S. H., and Wise, H. Comb. and Flame 10, 287-94 (1966).

[8] Lask, G., and Wagner, H. Gg., Eighth Symposium (International) on Combustion, p. 432 (Williams \& Wilkins, Baltimore, 1962).

[9] Halpern, C. J., Nat Bur. Stand. (U.S.), 67A, (Phys. and Chem.), No. 1, 71-77 (Jan.-Feb. 1963).

[10] Miller, D. R., Evers, R. L., and Skinner, G. B., Comb. and Flame 7, 137-42 (1963).

[11] Simmons, R. F., and Wolfhard, H. G., Trans. Faraday Soc. 52. $53-9$ (1956).

[12] Skinner, G. B., and Ringrose, G. H., J. Chem. Phys. 43, 4129-33 (1965).

[13] Cretiz, E. C., Nat. Bur. Stand. (U.S.), 65A (Phys. and Chem.) No. 4, 389-396 (July-Aug. 1961).

[14] Arthur, J. R., and Bowring, J. R., J. Chem. Soc. (London) (Proc.) (1949) S1-S12.

[15] Bridger, G. W., and Appleton, H. J., Soc. Chem. Ind. 67, 445-9 (1948).

[16] Brabbs, T. A., and Belles, F. E., Eleventh Symposium (International) on Combustion pp. 125-35 (1967). The Combustion Institute, Pittsburgh.

[17] Brokaw, R. S., Eleventh Symposium on Combustion pp. 1063-73 (1967). The Combustion Institute, Pittsburgh.

[18] Hoare, D. E., and Milne, G. S., Trans. Faraday Soc. 63, 101-110 (1967).

[19] Baldwin, R. R., Jackson, D., Walker, R. W., and Webster, S. J., Tenth Symposium (International) on Combustion pp. 423-32 (1965). The Combustion Institute, Pittsburgh.

[20] Fenimore, C. P., and Jones, G. W., J. Phys. Chem. 62, 178-83 (1958).

[21] Phillips, L. F., and Sugden, T. M., Trans. Faraday Soc. 57, 914-20 (1961).

[22] Wilson, W. E., Tenth Symposium (International) on Combustion pp. 47-54 (1965). The Combustion Institute, Pittsburgh.

[23] The Matheson Gas Data Book, 4th ed. (The Matheson Co. Inc., E. Rutherford, N.J.).

[24] Ung, A. Y-M, and Schiff, H. I., Canadian J. Chem. 40, 486-94 (1962).

[25] Ibiricu, M. M., and Gaydon, A. G., Comb. and Flame 8, 51-62 (1964).

[26] Miyama, H., and Takeyama, T. J., Chem. Phys. 41, 2287-90 (1964).

[27] Schofield, K., Planet. Space Sci. 15, 643 (1967).

[28] Mayer, S. W., and Schieler, L., J. Phys. Chem. 72, 236 (1968).

[29] Baldwin, R. R., Simmons, R. F., and Walker, R. W., Trans. Faraday Soc. 62, 2476-85 (1966).

[30] Baldwin, R. R., Simmons, R. F., and Walker, R. W., Trans. Faraday Soc. 62, 2486-98 (1966).

[31] Rosser, W. A. Jr., Wise, H., and Miller, J., Seventh Symposium (International) on Combustion pp. 175-82 (Butterworths, London, 1959).

[32] Fish, A., Comb. and Flame 8, 84-5 (1964).

[33] Tunder, R., Mayer, S., Cook, E., and Schieler, L., Aerospace Corp., Thermochemistry Res. Dept., Aerospace Report TR-1001 (9210-02)-1 (1967).

[34] Clyne, M. A. A., and Stedman, D. H., Trans. Faraday Soc. 62, 2164-74 (1966).

[35] Jensen, D. C., and Kurzius, S. C., AeroChem Res. Lab., Princeton, N.J., March 1967. Report TP-149.

[36] Blackmore, D. R., O'Donnell, G., and Simmons, R. F. Tenth Symposium (Internat'l) on Combustion pp. 303-10 (1965). The Combustion Inst., Pittsburgh.

[37] Fenimore, C. P., and Jones, G. W., Tenth Symposium (International) on Combustion, pp. 489-93 (1965), The Combustion Institute, Pittsburgh. 
[38] Getzinger, R. W., Eleventh Symposium (International) on Combustion, pp. 117-24 (1967), The Combustion Institute, Pittsburgh.

[39] McEwan, M. J., and Phillips, L. F., Comb. and Flame 11, 63-70 (1967).

[40] Urey, H. C., and Bates, J. R., Phys. Rev. 34, 1541 (1929).

[41] Vaidya, W. M., Proc. Indian Acad. Sci. 6A, 122-8 (1937).

[42] Vaidya, W. M., Proc. Indian Acad. Sci. 7A, 321 (1938).

[43] Coleman, E. H., and Gaydon, A. G., Disc. Faraday Soc. 2, 166-9 (1947).

[44] Coleman, E. H., Gaydon, A. G., and Vaidya, W. M., Nature 162, 108-9 (1948).

[45] Pannetier, G., and Gaydon, A. G., Nature 61, 242-3 (1948).

[46] Zeelenberg, A. P., Nature 181, 42 (1958).

[47] Porter, G., Proc. Roy Soc. (London) A200, 284-300 (1949-50).

[48] Porter, G., Science 160, 1299-1307 (1968).

[49] Durie, R. A., and Ramsay, D. A., Canadian J. Phys. 36, 35-53 (1958).

[50] Carrington, A., and Levy, D. H., J. Chem. Phys. 44, 1298-9 (1966).

[51] Norman, I., and Porter, G., Nature 174, 508-9 (1954).

[52] Norman, I., and Porter, G., Proc. Roy Soc. (London) A230, 399-414 (1955).

[53] Amano, T., Saito, S., Hiroto, E., Morino, Y., Johnson, D. R., and Powell, F. X., J. Mol. Spectr. 30, 275 (1969).

[54] Powell, F. X., and Johnson, D. R., J. Chem. Phys. 50, 4596 (1969).

[55] Clyne, M. A. A., and Coxon, J. A., Trans. Faraday Soc. 62, 1175-89 (1966).

[56] Niki, H., and Weinstock, B. J., Chem. Phys. 47, 3249-52 (1967).

[57] Clyne, M. A. A., and Coxon, J. A., Trans. Faraday Soc. 62, 2175-82 (1966).

[58] Johnson, D. R., and Powell, F. X., private communication.

[59] Porter, G., and Wright, F. J., Disc. Faraday Soc. 14, 23 (1953).

[60] Burns, G., and Norrish, R. G. W., Proc. Roy Soc. (London) A271 289-95 (1963).

[61] Evans, W. H., Munson, T. R., and Wagman, D. D. J. Research NBS 55, 147-64 (1955) RP 2614.
[62] Norrish, R. G. W., and Thrush, B. A., Quarterly Review 10. 149-168 (1956).

[63] Broida, H. P., Schiff, H. I., and Sugden, T. M., Nature 185, 759-60 (1960).

[64] Clyne, M. A. A., and Coxon, J. A., Proc. Roy Soc. (London) A303, 207-31 (1968).

[65] Westenberg, A. A., and Fristrom, R. M., J. Phys. Chem. 65, 591-601 (1961).

[66] Westenberg, A. A., and Fristrom, R. M., Tenth Symposium (International) on Combustion, pp. 473-83 (1964). The Combustion Institute, Pittsburgh.

[67] Bascombe, K. N., Reaction Rate Data. The Hydrogen/Oxygen System, Ministry of Aviation, Explosives Research and Development Establishment, Waltham Abbey, Essex, England, E.R.D.E. 1/S/65.

[68] Bahn, G. S., Pyrodynamics 5, 221-72 (1967).

[69] Baulch, D. L., Drysdale, D. C., and Lloyd, A. C., High Temperature Reaction Rate Data, Report No. 1 (May 1968), Dept. of Phys. Chem., The University, Leeds, England.

[70] Kaufman, F. Ann. Geophys. 20, 106-114 (1964).

[71] Johnston, H. S., Nat. Stand. Ref. Data Ser., Nat. Bur. Stand. (U.S.), 20, 54 pages (Sept. 1968).

[72] Kaufman, F. Proc. Roy Soc. (London) A247, 123-39 (1958).

[73] Cherry, S. S., Gold, P. I., and Van Nice, L. J., TRW Systems, Redondo Beach, California, Report 08832-6001-T0000.

[74] Clyne, M. A. A., and Stedman, D. H., Trans. Faraday Soc. 64, 2698 (1968).

[75] Ip, J. K. K., and Burns, G., J. Chem. Phys. 51, 3414-24 (1969).

[76] Porter, G., and Smith, J. A., Nature 184, 446-7 (1959).

[77] McEwan, M. J., and Phillips, L. F., Trans. Faraday Soc. 62, 1717-20 (1966).

[78] Unpublished results, E. C., Creitz, Fire Research Section, National Bureau of Standards.

[79] Lloyd, A. C., and Garvin, D., National Bureau of Standards, private communication.

[80] Greiner, N. R., J. Chem. Phys. 51, 5049-51 (1969).

[81] Tanford, C., and Pease, R. M., J. Chem. Phys. 15, 431 (1947).

(Paper 74,A4-618) 